\title{
Relationship between turbidity and total suspended solids concentration within a combined sewer system
}

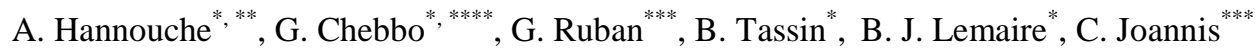 \\ * LEESU (formerly Cereve) - Université Paris-Est / AgroParisTech - 6-8, avenue Blaise Pascal - \\ Cité Descartes - Champs-sur-Marne - 77455 Marne-la-Vallée Cedex 2 - France (e-mail addresses: \\ ali.hannouche@leesu.enpc.fr, chebbo@leesu.enpc.fr, tassin@leesu.enpc.fr, bruno.lemaire@leesu.enpc.fr) \\ ** SEPIA Conseils, 53 rue de Turbigo, 75003 - Paris - France \\ *** LCPC - Division for Water and the Environment - route de Bouaye - BP 4129 - 44341 Bouguenais \\ Cedex -France (e-mail: Gwenael.Ruban@lcpc.fr, claude.joannis@lcpc.fr) \\ **** Faculty of Engineering III - Lebanese University - Hadath - Beirut - Lebanon
}

\begin{abstract}
This article confirms the existence of a strong linear relationship between turbidity and total suspended solids (TSS) concentration. However, the slope of this relation varies between dry and wet weather conditions, as well as between sites. The effect of this variability on estimating the instantaneous wet weather TSS concentration is assessed on the basis of the size of the calibration dataset used to establish the turbidity - TSS relationship. Results obtained indicate limited variability both between sites and during dry weather, along with a significant inter-event variability. Moreover, turbidity allows an evaluation of TSS concentrations with an acceptable level of accuracy for a reasonable rainfall event sampling campaign effort.
\end{abstract}

Keywords: Turbidity, TSS concentration, Dry weather, Wet weather, Variability, Calibration.

\section{INTRODUCTION}

Since 1970, many studies have highlighted the pollution from urban wet weather discharges and its negative impact on receiving water (Ellis and Hvitved Jacobsen, 1996, Gromaire et al., 2001, Saget et al., 1995, Smullen et al., 1999). Total suspended solids (TSS) constitute the main vector of contaminants during wet weather periods in combined sewer system (Ashley et al., 2005, Chebbo et al., 1995). French regulation requires the treatment wet weather flow for all ordinary events, as well as the monitoring of pollution before any discharge in the receiving system. Thus continuous TSS concentration measurements become essential. Currently, the TSS can be directly measured only in laboratory on samples collected during rain events, there is no continuous measuring device on the market yet, TSS concentration was estimated on the basis of laboratory analyses on samples collected during rain events. This introduces numerous constraints and error sources, namely: discrete sample collection, site-to-laboratory transport, sample packing and preservation, long waiting time for results, high cost, and as a consequence, only a limited number of events can be sampled each year (Bertrand-Krajewski et al., 2008). This leads to a poor temporal knowledge of the dynamics of solid transport phenomena and of its variability, as well as a great uncertainty regarding the evaluation of annual TSS flows (Mourad et al., 2005).

Continuous turbidity measurement in sewer systems is a real improvement and is more and more used as it allows a direct access to the dynamics of particule pollution, especially during rainfall events. Recent studies have demonstrated how it can be used to control and evaluate effluent quality (Langeveld et al., 2005, Lawler et al., 2006), but it must be emphasized that the use of suitable methods is mandatory to obtain reliable and accurate continuous turbidity measurements within the sewer system over short time steps (Joannis et al., 2008).

Turbidity monitoring allows us to assess TSS flows at both the event and annual scale with a small dispersion compared to more conventional sampling methods (Lacour et al., 2009a, Métadier M., Bertrand-Krajewski J.-L., 2011). However the turbidity TSS relationship still raises several concerns (Bertrand Krajewski et al., 2010, Ruban, 1995). Actually it depends on several parameters, 
notably the geometric and optical characteristics of suspended particles, which are highly variables and heterogeneous in urban stormwater and wastewater at both inter (between events) and intra (during the event) events scales. These parameters are correlated with the effluent quality and may vary during dry weather at the hour time scale, and during wet weather according to the rainfall event, also they vary during one rainfall event. This relationship is therefore neither unique nor consistent. Yet average relationships can be derived that are representative of various contexts (e.g. wet weather conditions, dry weather days, site-specific), and are quite effective at a yearly time scale (Fletcher and Deletic, 2007) and for a given site.

In this context, the present paper aims to: a) study and evaluate the variability in the relationship between turbidity and TSS concentration, between sites, under both dry and wet weather conditions; b) confirm the existence of a strong linear relationship between turbidity and TSS concentration; and c) assess the effect of this variability on estimations of the TSS concentration value, i.e. concentration uncertainties as a function of available calibration data.

Firstly we present the databases used. Then we explain the methodology developed to assess the variability of the turbidity-TSS relationship and of the TSS concentration. Finally the results obtained are discussed.

\section{METHODOLOGY}

\section{Experimental data}

\section{Site descriptions}

Nantes is one of the sites of the French urban hydrology observatories network (HURRBIS: Hydrologie Urbaine Réseau de Recherche Bassins Inter-Sites), located in the western part of France.

Turbidity and TSS were monitored for several years by the Laboratoire Central des Ponts et Chaussées (LCPC) Water and Environment Division on two catchments served by a combined sewer system: Saint-Mihiel (SM) and Cordon Bleu (CB)

The first site, SM, is representative of a small catchment encompassing a 100-hectare surface of dense urban area in the city center. The second site, CB, is much larger (5000 hectares) and embeds $\mathrm{SM}$. The catchment of CB is located downstream of the main collector of the city of Nantes (right bank of the river Loire), serving approximately 500000 population equivalent (Jaumouillié, 2003). This catchment extends from the city center to residential suburban areas, the latter being serviced by separate sewer systems.

\section{Databases available to this study}

During dry weather, six 24-hour instantaneous measurement campaigns were performed at CB and two at SM in order to establish turbidity-TSS relationship. The samples in the dry weather conditions were sampled instantaneously every two hours or so.

30 events were sampled under wet weather conditions at CB and 26 at SM. The samples in wet weather conditions were sampled instantaneously every ten minutes when the height of water in the sewer system exceeds a threshold height that is a criterion to define the rainfall event. Both Turbidity and TSS were measured on theses samples. Return periods of the 1-hour maximum rainfall intensity vary between 3 months and 10 years (two extreme events at CB); i.e. $11 \mathrm{~mm} / \mathrm{hr}$ for a 6-month return period, $13 \mathrm{~mm} / \mathrm{hr}$ for a 1-year return period and $21 \mathrm{~mm} / \mathrm{hr}$ for a 10 year one.

Both turbidity and TSS were measured in the laboratory on the same samples. Turbidity was measured while complying with the ISO 7027 (NF EN ISO 7027, 2000) standard by means of light attenuation within the infrared band at $880 \mathrm{~nm}$ using a turbidimeter manufactured by Ponsel. This 
turbidimeter was calibrated with formazin. As a consequence turbidity is expressed in formazin attenuation units (FAU). The TSS concentrations were determined according to AFNOR Standards (NF EN 872, 2005).

Wet weather definition is based on the water level within the collector, and wet weather sampling starts when water height corresponds to a doubling of the peak dry weather flow.

(T, TSS) pairs were validated on the basis of the "Cook's distance" statistical test (Cook, 2000). Table 1 summarizes the turbidity-TSS database.

\section{Theoretical turbidity-TSS relationship}

Turbidity reflects the loss of transparency in a liquid, i.e. in our case urban wastewater or stormwater, due to the presence of colloidal and/or suspended solids. Mie's theory (Mishendo et al., 1999), for $n$ classes of homogeneous suspended particles with a given size and refraction index, is able to demonstrate that the relationship between turbidity measured in attenuation $(T)$ and TSS concentration (TSS) is linear, i.e.:

$T S S=\frac{2}{3}\left(\sum_{i=1}^{n} \frac{Q_{e x t i} p_{m i}}{\rho_{p i} d_{p i}}\right)^{-1} T=a \times T$

$\mathrm{Q}_{\text {exti }}$ the characteristic extinction coefficient of class $i$ (which depends on the wavelength, refraction index and particle shape), $\rho_{p i}$ the mass density of class $i$ particles, and $p_{m i}$ the fraction of class $i$ particles with an equivalent diameter of $d_{p i}$.

The coefficient of proportionality $a$ between TSS concentration (TSS) and turbidity ( $T$ ) thus depends on the geometric and optical characteristics of the suspended particles (i.e. size, shape, refraction index, mass density).

For urban wastewater or stormwater, the TSS characteristics are both heterogeneous and variable with time. This explains why $a$ is able to vary with time, during dry weather at various time scales ranging from the hour to the season, and during wet weather, either between events or inside a same event.

In the following $a_{i j}$ will denote the value of the ratio of TSS concentration to the associated turbidity for sample $j$ of rainfall event or sampling campaign $i$.

Table 1| Details of the TSS -Turbidity value pairs at the CB and SM study sites

\begin{tabular}{|c|c|c|c|c|}
\hline \multirow{2}{*}{} & \multicolumn{2}{|c|}{ Wet weather } & \multicolumn{2}{c|}{ Dry weather } \\
\cline { 2 - 5 } & $\begin{array}{c}\text { Number of rainfall } \\
\text { events }\end{array}$ & Number of samples & $\begin{array}{c}\text { Number of sampling } \\
\text { campaigns (day) }\end{array}$ & Number of samples \\
\hline CB & 30 & 324 & 6 & 55 \\
\hline SM & 26 & 243 & 2 & 19 \\
\hline
\end{tabular}

\section{Calculation methods}

Analysis of the variability in ratio $a_{i j}$

Our aim is to evaluate the $a_{i j}$ 's variability, from one site to the other, spanning both dry and wet weather conditions, and on each particular site when alternating from one dry weather day to another and from one rainfall event to another.

Let's assume $k$ groups of observations (e.g. $k$ events or $k$ dry days or $k$ sites) $G_{1}, G_{2}, \ldots, G_{k}$ with respectively $n_{1}, n_{2}, \ldots, n_{k}$ records. Average values can be calculated for each group and for the pooled values: 
$a_{i}=\frac{1}{n_{i}} \sum_{j} a_{i j}$ and $a=\frac{1}{\sum_{i} n_{i}} \sum_{i} \sum_{j} a_{i j}$

The overall variability $S S_{T}$ may be divided into two types: at the inter-scale (e.g. inter-event), and at the intra-scale (e.g. during a single event). The decomposition can then be written in the following form:

$$
\begin{gathered}
S S_{T}=S S_{\text {int } e r}+S S_{\text {int } r a} \\
\sum_{i=1}^{k} \sum_{j=1}^{n_{i}}\left(a_{i j}-a\right)^{2}=\sum_{i=1}^{k} n_{i}\left(a_{i}-a\right)^{2}+\sum_{i=1}^{k} \sum_{j=1}^{n_{i}}\left(a_{i j}-a_{i}\right)^{2}
\end{gathered}
$$

The first term reflects inter-group variability $\left(S S_{\text {int } e r}\right)$, while the second term accounts for for intragroup variability taking place within the observation groups $\left(S S_{\text {int } r a}\right)$.

The correlation ratio then yields the share of total variability in the data explained by the group effect, i.e.:

$$
R^{2}=100 * \frac{S S_{\text {inter }}}{S S_{T}}
$$

This variability index ranges between 0 and 100 and will be used to characterize inter-group variability with respect to total variability. The index value tends to 0 if intra-group variability is predominant.

This global approach was completed by an analysis of the homogeneity existing among the various groups $G_{i}$ by means of statistical significance testing (5\% threshold) using both Wilcoxon-MannWhitney ( $k=2$ comparison between sites) and Kruskal-Wallis ( $k>2$ : comparison between events or between dry days) (Corder and Foreman, 2009).

\section{Evaluation of wet weather TSS concentration: Regression calculations - Monte Carlo simulation}

Since $a_{i j}$ values vary depending on the characteristics of suspended solids, empirical relationships are used in practice to convert turbidity values into TSS concentrations. We began by establishing a linear relationship specific to each rainfall event and each dry weather sampling campaign through applying the ordinary least squares regression: $T S S=a T+b$. These regression lines do not necessarily pass through the origin. Choosing a linear regression model that does not pass through the origin implicitly recognizes that the model cannot be extrapolated for very low values: a zero turbidity value would therefore correspond to nonzero (and even negative) TSS values. This acknowledges that particle characteristics vary over the course of a single day or during a given event, but suggests that these variations are in fact correlated with the TSS concentration value. Moreover, the wet weather samples at both the CB and SM sites showed turbidity values varying between 100 and $700 \mathrm{FAU}$, i.e. the most probable range of values in a combined sewer during wet weather (Lacour et al., 2009b). As a result, we calculated the TSS concentration for turbidity values lying between 100 and 700 FAU.

After analyzing the variations in these relationships, the next step consisted of examining the possibility of combining events in order to calculate a single regression, and to study the impact of sampled events on TSS uncertainty, using a Monte Carlo simulation. To perform this study we assume that the pool of actually sampled events is representative of events capable of occurring on each catchment basin. Then we simulate simpler measurement campaigns, which would entail a smaller number of events. To proceed, a number of events $\mathrm{n}$ was randomly drawn from among the events numbered 1 through $\mathrm{N}$ for each site (where $\mathrm{n} \leq \mathrm{N}$, see Table 1), without replacement for each 
n-event set; then, for each selected set, a turbidity-TSS regression could be calculated, and the process is repeated 1000 times for each value of $n$.

Each turbidity value thus yielded a distribution of TSS concentration values, and this distribution corresponded to the dispersion in average relationships derived from the various event datasets. TSS concentration variability was expressed in terms of half-confidence intervals because we have verified, using the Shapiro-Wilk normality test at the 5\% threshold, that for $n \geq 2$, the normal distribution of TSS concentration is readily accepted

Moreover, for a particular set of calibration events, the regression model implies residual errors. These errors were assumed to follow a normal law with a variance $\sigma^{2}$ derived from residues observed for calibration data. The normality of all residues were verifed without the two extreme events at CB using the Shapiro-Wilk normality test at the 5\% threshold. The simulated TSS concentration value was thus derived by simulating a random number $\tau$ that followed a Student's $t$ distribution with $n_{\text {sample }}-2$ degrees of freedom, where $n_{\text {sample }}$ is the number of samples introduced to adjust the linear regression line. The simulated TSS value, for a given turbidity $T_{i}$, then equals:

$$
T S S_{\text {simu }}=T S S_{L R}+s \sqrt{\left(1+\frac{1}{n_{\text {sample }}}+\frac{\left(T_{i}-\bar{T}\right)^{2}}{\sum_{j=1}^{n_{\text {sample }}}\left(T_{j}-\bar{T}\right)^{2}}\right)} \tau_{\left(n_{\text {sample }}-2\right)}
$$

with $T S S_{L R}=a T_{i}+b$ being the value of TSS concentration estimated by the linear regression line for parameters $a$ and $b, s$ the estimated residual standard deviation, and $\bar{T}$ the average turbidity value of all samples $T_{j}$.

The Student's $t$ distribution exhibits infinite variance for fewer than 3 degrees of freedom; hence, we removed from the analysis those sets of calibration events whose $n_{\text {sample }}$ values were below 5 .

This process was then reiterated a maximum of 1,000 times for each given sub-sample $n$ and turbidity value $T_{i}$.

\section{RESULTS AND DISCUSSION}

\section{Analysis of the variability in ratio $a_{i j}$ between TSS and turbidity}

The ratios $a_{i j}$ are illustrated in the form of Tukey box-and-whisker plots (see Fig. 1a); the lower and upper lines of the box correspond respectively to the $1^{\text {st }}$ and $3^{\text {rd }}$ quartiles $\left(Q_{1}\right.$ and $\left.Q_{3}\right)$, while the median $\left(Q_{2}\right)$ and mean (dotted line) are represented by horizontal lines inside the box. Both the lower and upper whiskers delimit so-called "adjacent" values, which are determined on the basis of the inter-quartile deviation $I Q R=Q_{3}-Q_{1}$ and which equal $Q_{1}-1.5 * I Q R$ and $Q_{3}+1.5 * I Q R$. In addition to these values, so-called extreme values extending beyond the adjacent values have been treated individually and represented by markers (wet weather in our case)

The CB site displays dispersion in this ratio of lesser magnitude than SM site dispersion during both dry and wet weather periods. The wet weather dispersion as given by adjacent values is on the order of $30 \%$ with respect to the median value at CB, and $40 \%$ at SM. The extreme values of $a_{i j}$ represent 10 -year rainfall events and are significantly higher than the rest of the data recorded. For the other values, no trend can be detected relative to any of the general characteristics applicable to the surveyed events. The dry weather ratios are less variable and display lower overall values than their wet weather counterparts; this result can be explained by the type of particles involved during wet 
weather (i.e. less homogeneous, more mineral in nature, finer-grained, see (Joannis, Ruban et al., 2008).

Inter-site variability during dry and wet weather periods

Figures $1 a$ and $b$ indicate that the values of $a_{i j}$ are comparable at the two sites during dry weather. This explains the correlation ratio equal to 6\% (Fig. 2). In addition, the Wilcoxon-Mann-Whitney statistical test confirmed the non significance of the variability of $a_{i j}$ between sites at the 5\% threshold. This result underscores the relative spatial homogeneity of $a_{i j}$, during dry weather. Such homogeneity has also been observed by "Marechal, (2000)" at various sites during dry weather for attenuation-based turbidity measurements. It would be worthwhile to verify this latest conclusion for Nephelometric turbidity measurements.

Similarly, during wet weather, Figures $1 a$ and 2 attest to a relative homogeneity of $a_{i j}$ at both sites. The small spatial variability found in $a_{i j}$ values is also noticed when performing statistical analyses. This initial observation suggests that the quality of wet weather, combined sewer effluent remains rather homogeneous when examined from spatial scale larger than a few dozen hectares (Kafi et al., 2008).

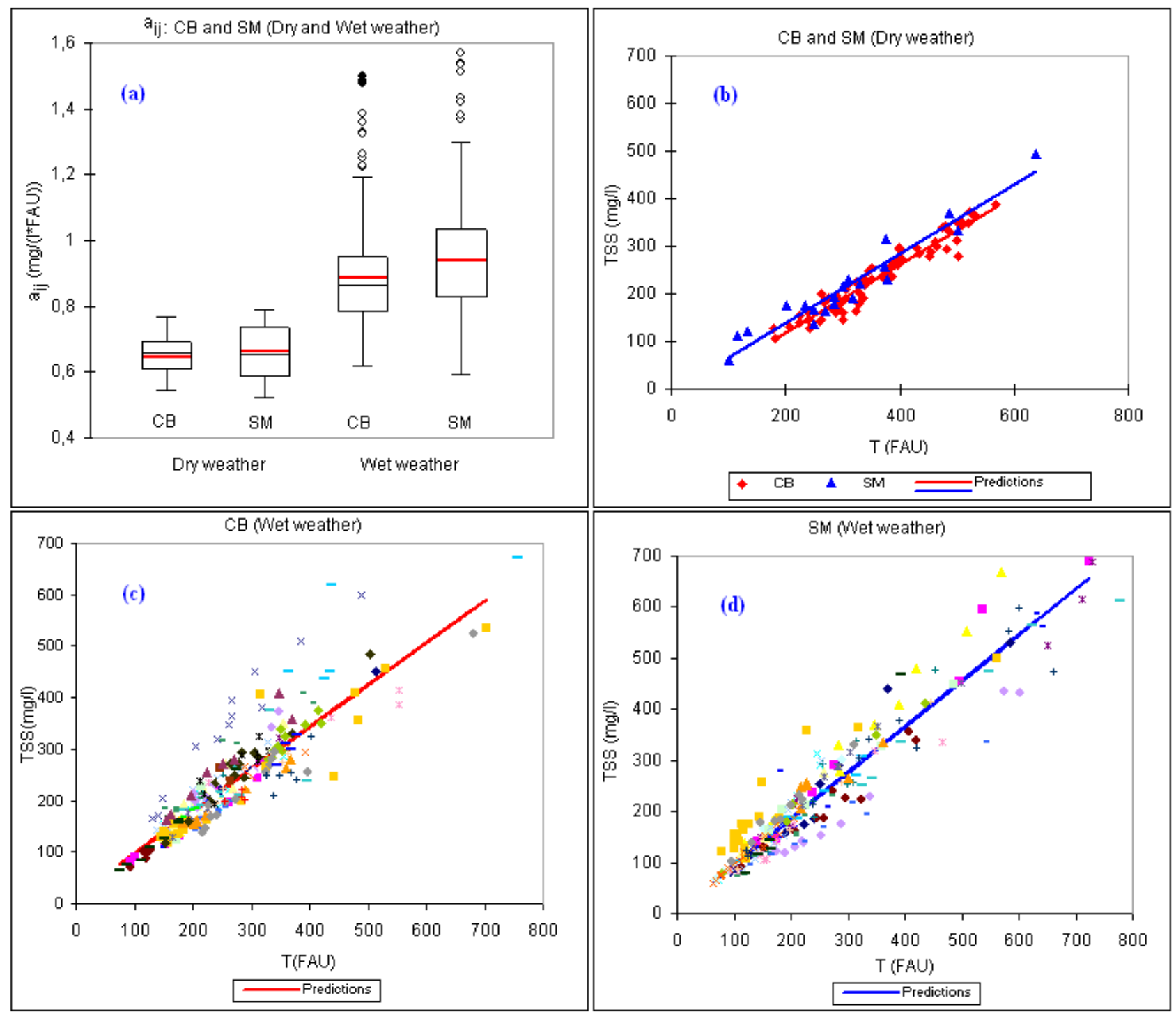

Figure 1| a) Box plots of $a_{i j}$ ratio at SM and CB during dry and wet weather periods; b, c and d) Relationships between TSS and turbidity at the CB and SM sites during dry and wet weather periods (the various symbols represent individual events) 


\section{Dry weather variability}

The variability over the course of any given day is slightly predominant over the variability between different days and amounts to $60 \%$ of total CB site variability and to $65 \%$ at SM (Fig. 2). Anyway the Kruskal-Wallis statistical test asserts the significance of the variability of aij between days at the $5 \%$ threshold

\section{Variability between rain events}

The variability of $a_{i j}$ between rainfall events is noteworthy. More than $70 \%$ of the total wet weather variability is inter event variability (Fig. 2). Such an inter-event variability confirms the findings of (Chebbo, 1992, Kafi-Benyahia et al., 2005) regarding wet weather pollutant characteristics. Yet it could not be correlated with general characteristics of rainfall events, such as precipitated height, intensity and previous dry weather period duration.

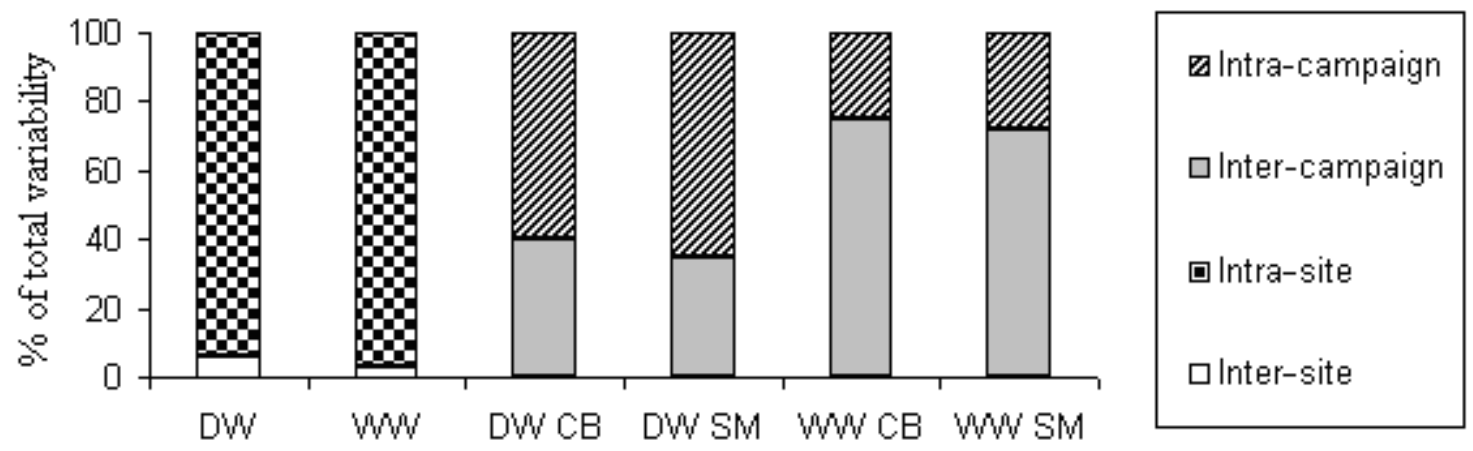

Figure 2| Percentage of inter-group and intra-group variability with respect to total group variability (DW: dry weather days, WW: wet weather events, CB: Cordon Bleu, SM: Saint Mihiel)

\section{Quality of the linear relationships between turbidity and TSS}

Table 2 lists parameters describing the linear relationships between turbidity and TSS for the SM and CB sites. It reveals good linearity of these relationships, and most of them tend to pass close to the origin under all weather conditions. The presence of two strong events in $\mathrm{CB}$ deviate the regression line of the overall relationship at $\mathrm{CB}$. So we observe cetraine difference between the wet weather $b$ median value and overall $b$ value. But the variability of the slope $a$ is similar to the variability of the ratio aij described in a preceding section.

These results signify that variations of particle characteristics over the course of a given rainfall event or dry weather day are not sufficient to change turbidity-TSS relationships. The low variability of the slope exerts an impact on the linear relationship built using the data points of all events. The coefficients of determination found for these linear relationships are in fact slightly less than the median of all relationships taken as a whole, yet still remain above 0.8 .

Table 2| Parameters used to derive the turbidity-TSS relationships ( $T S S=a T+b)$ for both the CB and SM databases during wet weather (WW) and dry weather (DW) for all samples as in Table 1 ( $s_{b}$ and $s_{a}$ are the standard deviations of $a$ and $b$ )

\begin{tabular}{|c|c|c|c|c|}
\hline \multicolumn{2}{|c|}{} & CB & SM \\
\hline \multirow{2}{*}{$\begin{array}{c}\text { Coefficient of } \\
\text { determination } r^{2}\end{array}$} & Median & 0.92 & 0.97 \\
\cline { 2 - 5 } & $\begin{array}{c}T S S \text {-intercept } b \\
\left(m g . l^{-1}\right)\end{array}$ & Empirical, 95\% CI & {$[0.74 ; 0.98]$} & {$[0.80 ; 0.99]$} \\
\cline { 3 - 5 } & & Median & 0 & -5 \\
\hline
\end{tabular}




\begin{tabular}{|c|c|c|c|c|}
\hline \multirow{7}{*}{ WW } & $\begin{array}{c}\text { Slope } a \\
\left(m g \cdot l^{-1} . F A U^{-1}\right)\end{array}$ & Empirical, 95\% CI & {$[0.63 ; 1.23]$} & {$[0.60 ; 1.17]$} \\
\cline { 2 - 5 } & $R^{2}$ & Overall relationship & 0.82 & 0.82 \\
\cline { 2 - 5 } & $b \pm s_{b}$ & Overall relationship & $15 \pm 7$ & $7 \pm 5$ \\
\cline { 2 - 5 } & $a \pm s_{a}$ & Overall relationship & $0.85 \pm 0.02$ & $0.89 \pm 0.02$ \\
\hline \multirow{4}{*}{ DW } & $r^{2}$ & Overall relationship & 0.93 & 0.93 \\
\cline { 2 - 5 } & $b \pm s_{b}$ & Overall relationship & $-8 \pm 9$ & $-6 \pm 16$ \\
\cline { 2 - 5 } & $a \pm s_{a}$ & Overall relationship & $0.71 \pm 0.02$ & $0.72 \pm 0.05$ \\
\hline
\end{tabular}

\section{Uncertainty in the TSS concentration assessed from turbidity}

Figure 3 shows the 95\% half-confidence intervals of TSS concentration, for the CB and SM sites. The impact of the number of events used to calibrate the turbidity-TSS relationship on the TSS concentration dispersion is in fact very easy to distinguish. The TSS concentration at CB stands out with a greater dispersion due to the presence of two 10-year events, which do not resemble any of the other events in terms of the calibration relationship established between turbidity and TSS concentration (Fig. 1c). As an example, in order to evaluate TSS concentration on the basis of turbidity measurement with a dispersion on the order of $\pm 20 \%$ within the $[150,700]$ FAU interval, it would be sufficient to sample at least 5 events. This number of events is apparently compatible with the duration of measurement campaigns conducted within the scope of sewer system diagnostic examinations. This finding demonstrates that the use of turbidity provides substantially improved accuracy in evaluating wet weather TSS.
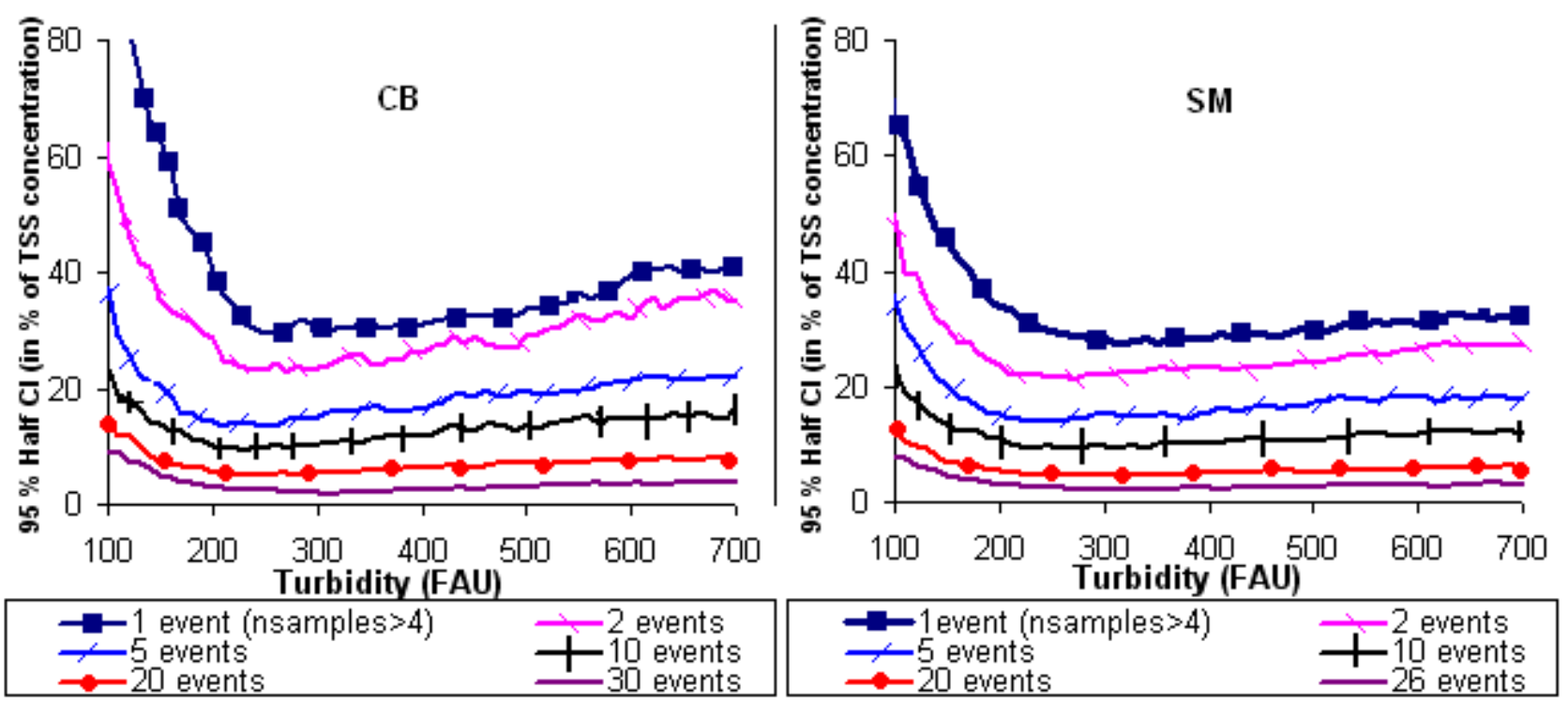

Figure 3| Dispersion of wet weather TSS concentration vs. turbidity, and number of sampled events taken into consideration for the $\mathrm{CB}$ and $\mathrm{SM}$ study sites

\section{CONCLUSION}

This study has confirmed the possibility to use turbidity to assess TSS concentration within a combined sewer system. The key findings of this work are as follows:

- The turbidity-TSS calibration relationships show good linearity regardless of weather conditions, and most of them tend to pass close to the origin.

- The ratio $a_{i j}$ between TSS concentration and turbidity varies from 0.5 to $0.8 \mathrm{mg} . \mathrm{l}^{-1} . F A U^{-1}$ in dry weather conditions and 0.6 to $1.4 \mathrm{mg}^{-1} \mathrm{l}^{-1} . F A U^{-1}$ for most rain events. 
- The inter-site variability of $a_{i j}$, is not significant at the 5\% threshold, regardless of weather conditions.

- The variability in aij is lower in dry weather conditions than during rain events. The variability from one dry weather day to another remains lower than the same-day variability.

- For rain events, the inter-event variability of aij largely exceeds the intra-event variability.

- To meet an operational objective, 5 events are sufficient to build an turbidity-TSS relationship capable of evaluating instantaneous, wet weather TSS concentration values in the $[150,700]$ FAU turbidity interval with a level of uncertainty remaining less than $20 \%$.

These satisfactory results are explained both by the method applied for correlating turbidity and TSS values measured at the laboratory on the same physical sample, and by a low inter-event variability in the linear turbidity-TSS calibration on the considered sites. Such limited variability allows for the use of continuous turbidity measurements in learning about solid transport phenomena occurring in the sewer network, especially regarding sedimentation / erosion processes. It would be worthwhile to pursue this line of research at other sites as a preliminary step to generalization

Regarding the method, it assumes that the turbidity values do not change between the sampling location and the laboratory. This point has not been thoroughly investigated yet and will be in the next future.

\section{ACKNOWLEDGMENTS}

This study has been performed within the framework of the OPUR research program. The authors gratefully acknowledge the SEPIA Conseils firm, the Municipality of Paris, the Interdepartmental Association for Sewage Disposal in the Paris Conurbation (SIAAP), the Seine-Normandy Water Agency (AESN), the Departmental Council of Seine-Saint-Denis (Water and Sewage Services Department - DEA 93), the Departmental Council of Val-of-Marne (Water and Sewage Services Department - DSEA 94) and the Paris Regional Council (CRIF) for their combined financial support. Thanks are also owed to the Nantes Metropolitan authority for its technical support.

\section{REFERENCES}

Ashley, R., Bertrand-Krajewski, J.L. and Hvitved-Jacobsen, T. (2005) Sewer solids - 20 years of investigation. Water Science and Technology 52(3), 73-84.

Bertrand-Krajewski, J.L., Barraud, S., Kouyi, G.L., Torres, A. and Lepot, M. (2008) On-line monitoring of particulate pollutant loads in urban sewer systems: stakes, methods, example of application. La Houille Blanche (4), 49-57.

Bertrand Krajewski, J.L., Joannis, C., Chebbo, G., Ruban, G., Métadier, M. and Lacour, C. (2010) Comment utiliser la turbidité pour estimer en continu les concentrations en MES et/ou DCO: Une approche méthodologique pour les réseaux d'assainissement (How to use turbidity for continuously assessing TSS and/or COD concentrations in sewer systems? A methodological approach) TSM. Techniques sciences méthodes, France (no1-2), pp. 36-46.

Chebbo, G. (1992) Solides des rejets pluviaux urbains. Caractérisation et traitabilité (Solids in urban wet weather discharges: characterization and treatment), $\mathrm{PhD}$ Thesis, Ecole Nationale des Ponts et Chaussées, Paris, France (in French).

Chebbo, G., Bachoc, A., Laplace, D. and Leguennec, B. (1995) The transfer of solids in combined sewer networks. Water Science and Technology 31(7), 95-105.

Cook, R.D. (2000) Detection of influential observation in linear regression. Technometrics 42(1), 65-68.

Corder, G.W. and Foreman, D.I. (2009) Nonparametric Statistics for Non-Statisticians: A Step-byStep Approach, John Wiley \& Sons, Inc., Hoboken, New Jersey. 
Ellis, J.B. and Hvitved Jacobsen, T. (1996) Urban drainage impacts on receiving waters. Journal of Hydraulic Research 34(6), 771-783.

Fletcher, T.D. and Deletic, A. (2007) Statistical evaluation and optimisation of stormwater quality monitoring programmes. Water Science and Technology 56(12), 1-9.

Gromaire, M.C., Garnaud, S., Saad, M. and Chebbo, G. (2001) Contribution of different sources to the pollution of wet weather flows in combined sewers. Water Research 35(2), 521-533.

Jaumouillié, P. (2003). Hétérogénéités des vitesses et des concentrations dans les collecteurs

d'assainissement: application à la mesure des flux polluants (Heterogeneities velocities and concentrations in sewerage collectors: application to the measurement of flow pollutants), $\mathrm{PhD}$ thesis at the University of Bordeaux 1, $236 \mathrm{p}$.

Joannis, C., Ruban, G., Gromaire, M.C., Bertrand-Krajewski, J.L. and Chebbo, G. (2008) Reproducibility and uncertainty of wastewater turbidity measurements. Water Science and Technology 57(10), 1667-1673.

Kafi-Benyahia, M., Gromaire, M.G. and Chebbo, G. (2005) Spatial variability of characteristics and origins of urban wet weather pollution in combined sewers. Water Science and Technology 52(3), 53-62.

Kafi, M., Gasperi, J., Moilleron, R., Gromaire, M.C. and Chebbo, G. (2008) Spatial variability of the characteristics of combined wet weather pollutant loads in Paris. Water Research 42(3), 539549.

Lacour, C., Joannis, C. and Chebbo, G. (2009a) Assessment of annual pollutant loads in combined sewers from continuous turbidity measurements: Sensitivity to calibration data. Water Research 43(8), 2179-2190.

Lacour, C., Joannis, C., Gromaire, M.C. and Chebbo, G. (2009b) Potential of turbidity monitoring for real time control of pollutant discharge in sewers during rainfall events. Water Science and Technology 59(8), 1471-1478.

Langeveld, J.G., Veldkamp, R.G. and Clemens, F. (2005) Suspended solids transport: an analysis based on turbidity measurements and event based fully calibrated hydrodynamic models. Water Science and Technology 52(3), 93-101.

Lawler, D.M., Petts, G.E., Foster, I.D.L. and Harper, S. (2006) Turbidity dynamics during spring storm events in an urban headwater river system: The Upper Tame, West Midlands, UK. Science of the Total Environment 360(1-3), 109-126.

Marechal, A. (2000) Relations entre caractéristiques de la pollution particulaire et paramètres optiques dans les eaux résiduaires urbaines (Relationship between particulate pollution characteristics and optical parameters in wastewater), PhD Thesis, Institut national polytechnique de Lorraine, Vandoeuvre-lès-Nancy, France (in French).

Métadier M., Bertrand-Krajewski J.-L. (2011). From mess to mass: a methodology for calculating storm event pollutant loads with their uncertainties, from continuous raw data time series. Water Science and Technology, 63(3), 369-376.

Mishendo, M.I., Hovenier, J.W. and Travis, L.D. (1999) Light Scattering by Nonspherical Particles: Theory, Measurements, and Applications, Academic Press Inc 1999, 690 p..

Mourad, M., Bertrand-Krajewski, J.L. and Chebbo, G. (2005) Sensitivity to experimental data of pollutant site mean concentration in stormwater runoff. Water Science and Technology 51(2), 155162.

NF EN ISO 7027 (2000) Qualité de l'eau- détermination de la turbidité, "Water quality determination of turbidity", AFNOR, Paris - France, 14 p.

NF EN 872 (2005). Qualité de l'eau - Dosage des matières en suspension - Méthode par filtration sur filtre en fibres de verre, " Water quality - Determination of suspended solids - Method by filtration through glass fibre filters", AFNOR, Paris - France, 14 p.

Ruban, G. (1995) Continuous measurement of pollution due to urban effluents under wet conditions using optical-systems. Water Science and Technology 32(1), 241-247. 
Saget, A., Chebbo, G. and Desbordes, M. (1995) Urban discharges during wet weather - what volumes have to be treated. Water Science and Technology 32(1), 225-232.

Smullen, J.T., Shallcross, A.L. and Cave, K.A. (1999) Updating the US nationwide urban runoff quality data base. Water Science and Technology 39(12), 9-16. 